\title{
Assessment of the mosaic structure in the Helicobacter pylori cagA gene 3 -region using an improved polymerase chain reaction-based assay
}

\author{
Hans-Jurg Monstein, Anna Ryberg and Anneli Karlsson
}

\section{Linköping University Post Print}

N.B.: When citing this work, cite the original article.

Original Publication:

Hans-Jurg Monstein, Anna Ryberg and Anneli Karlsson, Assessment of the mosaic structure in the Helicobacter pylori cagA gene 3 -region using an improved polymerase chain reactionbased assay, 2012, Diagnostic microbiology and infectious disease, (73), 3, 281-283. http://dx.doi.org/10.1016/j.diagmicrobio.2012.03.017

Copyright: Elsevier http://www.elsevier.com/

Postprint available at: Linköping University Electronic Press http://urn.kb.se/resolve?urn=urn:nbn:se:liu:diva-79684 
Revised as Notes 2012

\title{
Assessment of the mosaic structure in the Helicobacter pylori cagA gene 3' - region using an improved PCR based assay
}

\author{
Hans-Jürg Monstein ${ }^{1 *}$, Anna Ryberg ${ }^{1}$, Anneli Karlsson ${ }^{2}$
}

${ }^{1}$ Division of Clinical and Experimental Medicine, Faculty of Health Sciences, Linköping University, Department of Clinical Microbiology, County Council of Östergötland, S-581 85 Linköping, Sweden

${ }^{2}$ Division of Clinical and Experimental Medicine, Department of Surgery, Faculty of Health Sciences, Linköping University, County Council of Östergötland, S-581 85 Linköping, Sweden

Article type: Notes

Key words: Molecular genotyping, amplicon sequencing, cagA EPIYA/T segment, cagA preEPIYA/T region, CagA multimerisation motif

*Corresponding author:

Dr. Hans-Jürg Monstein

Clinical Microbiology, University Hospital

Lab 1, floor 09, S-581 85 Linköping, Sweden

E-mail address: hans-jurg.monstein@liu.se 


\title{
Revised as Notes 2012
}

\begin{abstract}
The mosaic structure of the cagA gene has been suggested to affect $H$. pylori CagA associated pathogenesis. An improved PCR assay allowed for a rapid and detailed molecular analysis of the $\operatorname{cag} A$ gene 3 '-region in a single amplification step, followed by amplicon sequencing using universal M13 and T7 sequencing primers.
\end{abstract}

The Helicobacter pylori cagA gene is commonly used as a molecular virulence marker of H. pylori. DNA sequence analysis of the cagA gene has revealed the presence of a conserved 5'-region and a highly variable 3'-region [1-3]. Previous studies have shown that the CagA cytotoxin is directly injected into epithelial cells via a type IV secretion system, encoded by genes located in the cag - pathogenicity island (cag-PAI) $[1,4,5]$. In the host cell, CagA localises to the inner surface of the plasma membrane and undergoes phosphorylation on specific tyrosine residues within repeating penta amino acid Glu-Pro-Ile-Tyr-Ala (EPIYA) motifs, and in some cases Glu-Pro-Ile-Tyr-Thr (EPIYT), present at the C-terminus of the protein $[2,6,7]$. Tyrosine phosphorylation is carried out by host cell kinases such as Abl and Src $[6,8,9]$. The tyrosine phosphorylated CagA binds to a cytoplasmatic Src Homology 2 (SH2) domain of Src Homology 2 phosphatase 2 (SHP-2). A pre-requisite for CagA-SHP-2 interaction is CagA multimerisation, which is mediated by a conserved sequence of 16 amino acids (FPLXRXXXVXDLSKVG) identified and designated as the CagA multimerisation (CM) motif $[10,11]$. It is assumed that the CM sequence plays an important role in the stabilisation of CagA in gastric epithelial cells [11]. A recent study revealed differences in the in vitro biological activity of two H. pylori strains with different CM motifs (one Western and one East Asian), both strains from dyspeptic biopsy specimens [12]. 


\section{Revised as Notes 2012}

Recently, Uchida and co-workers [13] reported on the finding of a pre-EPIYA/T region located about $300 \mathrm{bp}$ upstream of the first EPIYA/T motif. They have shown that strains with an 18 bp or 39 bp deletion in the pre-EPIYA/T region possessed an EPIYA/T-D segment, whereas strains without any deletion commonly had an EPIYA/T-C segment [13]. In this study we used DNA isolated from 24 archival Helicobacter pylori strains (HJM1-18, 20-25), originally obtained from a routine clinical screening of non-ulcer dyspeptic (NUD) gastric biopsy specimens (mixed age and gender) collected at the Department of Clinical Microbiology, University Hospital Linköping Sweden [14]. Reference strain H. pylori 26695 [GenBank:NC_00015] was obtained from the American tissue culture collection (ATCC) (http://www.atcc.org/). H. pylori strains were cultured using an established clinical routine procedure [15]. Bacterial DNA was extracted [14], followed by multiple displacement amplification (MDA) using an Illustra GenomiPhi V2 DNA kit according to the manufacturer's instruction (GE-Healthcare, Uppsala, Sweden). Prior to MDA-amplification, the integrity of the bacterial DNA was analysed by $16 \mathrm{~S}$ rDNA amplification as described elsewhere [16].

Pre-EPIYA/T (18 bp or 39 bp deletion), EPIYA/T-A, -B, -C or -D segments, and the CagA multimerisation motifs were analysed using $2 \mu$ l MDA-DNA, 1x HotStarTaq-Master mix (Qiagen, Hilden Germany), and 10 pmol of each primer M13-p-EPIY.T5.se $\underline{\text { (TGTAAAACGACGGCCAGTAAGCGTTAGCCGATCTCAAA) and T7-CagA.EPIYA.as }}$ (TAATACGACTCACTATAGGGTGTGGCTGTTAGTAGCGTAATTGTC) (Fig. 1) in a final reaction volume of $25 \mu \mathrm{l}$. PCR amplification was performed using a 2720 Thermal Cycler (Applied Biosystems AB, Stockholm, Sweden) and the following amplification conditions: initial denaturation at $95{ }^{\circ} \mathrm{C}$ for $15 \mathrm{~min} ; 30$ cycles of $95{ }^{\circ} \mathrm{C}$ for $30 \mathrm{~s} ; 55^{\circ} \mathrm{C}$ for $30 \mathrm{~s} ; 72{ }^{\circ} \mathrm{C}$ for $90 \mathrm{~s}$; and a final extension at $72{ }^{\circ} \mathrm{C}$ for $10 \mathrm{~min}$. Prior to sequencing, amplicons were analysed by automated capillary gel electrophoresis (CGE) using a QIAxcel system and a QIAxcel 


\section{Revised as Notes 2012}

DNA Screening kit following the manufacturer's instructions (Qiagen, Hilden, Germany). Bidirectional amplicon sequencing was carried out using M13 uni (-21) and T7 sequencing primers and a custom sequencing service (Eurofins MWG Operon, Ebersberg, Germany). The obtained DNA sequences were translated into amino acid sequences, aligned and compared with the H. pylori 26695 [GenBank:NC_000915] sequence using the CLC DNA workbench software version 4.0 .

Sixteen of the $24 \mathrm{H}$. pylori strains analysed revealed EPIYA/T-ABC genotypes (Table 1, supplement S1). Moreover, alignment of the deduced amino acid sequences revealed frequent single amino acid mutations in the EPIYA/T segments (Supplement S1). H. pylori strain HJM6 and HJM12 possess an EPIYA/T-AABC genotype, whereas H. pylori strain HJM11 has an EPIYA/T-ABD genotype corresponding to the East Asian type (Supplement S1), including and a 39 bp-deletion in the pre-EPIYA/T region. H. pylori strain HJM1 has an EPIYA-ABCC genotype (Table 1, supplement S1). Three H. pylori strains (HJM16, HJM18 and HJM20) generated overlapping sequence-chromatograms that indicates the presence of multiple amplicons and no EPIYA genotypes could be established. DNA isolated from $H$. pylori strains HJM7 and HJM21 generated no amplicons, indicating either the absence of a functional cag-PAI or nucleotide mutations in the primer target sequence.

Amino acid sequence alignment revealed that the $\mathrm{N}$-terminal and $\mathrm{C}$-terminal sides of the EPIYA/T-C segments are flanked by Western CM motifs (Fig. 1B) in all cultured H. pylori strains with the exception of HJM11 (Supplement S1). The C-terminal CM motif flanking the EPIYA/T-D segment (Fig. 1C) present in strain HJM11 resembles amino acid sequences corresponding to the East Asian CM motif (Fig. 1; Supplement S1). Three H. pylori strains (HJM16, HJM18 and HJM20) generated overlapping sequence chromatograms that indicate the presence of multiple amplicons. Therefore, CM motifs could not be fully established. 


\section{Revised as Notes 2012}

Mixed amplicons derived from a randomly selected $H$. pylori strain MDA-DNA (HJM18) were cloned to establish the cagA EPIYA segment types as described elsewhere [17]. Eleven white colonies were picked and used directly in a confirmatory cagA EPIYA/T amplification assay as described above. Re-sequencing and CGE of the cloned amplicons revealed the presence of EPIYA/T -AB, -ABC, -ABCC and -ABCCC genotypes (Fig. 2). Amplicon sequencing and CGE analysis also revealed a bias of amplicons observed before (Fig. 2, lane 18) and after cloning (Fig. 2, lane 18a and 18h) which might be due to the fact that only highly abundant amplicons, present in the initial amplification derived from H. pylori HJM18MDA-DNA, were detectable by CGE.

Numerous PCR amplification assays have been described for the identification of the CagA EPIYA/T phosphorylation motif, including multiple PCR amplification steps and ethidium-bromide stained agarose gel electrophoresis (summarised in ref [18]). Commonly, amplicons are sequenced using a battery of gene specific primers (often the PCR primers). In a recent study, we described an improved strategy using M13 and T7 sequence tagged primers in PCR amplification covering the cagA EPIYA motifs. Tagging of the PCR primers enables rapid sequencing using universal M13 and T7 sequencing primers [18]. The result of our study are in agreement with recent studies where it has been shown that single amino acid sequence mutations, as well as CagA structural variants such as duplication and deletions, mediated by recombination events involving $\mathrm{CM}$ and EPIYA motifs, and recombination between short similar DNA sequences, frequently occur in the cagA gene 3' region[19].

In conclusion, we believe that the PCR based assay presented herein is a simple and rapid means to assess the Helicobacter pylori cagA gene 3'-region mosaic structure. Moreover, the methodological approach allowed a rapid detection of mixed $H$. pylori strains present in the same culture. 
Revised as Notes 2012

\section{Acknowledgments}

This study was supported by grants from the Research Council in the South-east of Sweden (FORSS), the ALF-program University Hospital, Linköping, the Committee for Medical Research and Development at the University Hospital, Linköping, and the Molecular Biology

Program at Clinical Microbiology, Laboratory Medicine Centre-DC, University Hospital, Linköping, Sweden. 


\section{References}

1. Covacci A, Censini S, Bugnoli M, Petracca R, Burroni D, Macchia G, Massone A, Papini E, Xiang Z, Figura N, et al.: Molecular characterization of the 128-kDa immunodominant antigen of Helicobacter pylori associated with cytotoxicity and duodenal ulcer. Proc Natl Acad Sci U S A 1993, 90:5791-5795.

2. Hatakeyama M: Helicobacter pylori CagA--a potential bacterial oncoprotein that functionally mimics the mammalian Gab family of adaptor proteins. Microbes Infect 2003, 5:143-150.

3. Yamaoka Y, Kodama T, Kashima K, Graham DY, Sepulveda AR: Variants of the 3' region of the cagA gene in Helicobacter pylori isolates from patients with different H. pylori-associated diseases. J Clin Microbiol 1998, 36:2258-2263.

4. Akopyants NS, Clifton SW, Kersulyte D, Crabtree JE, Youree BE, Reece CA, Bukanov NO, Drazek ES, Roe BA, Berg DE: Analyses of the cag pathogenicity island of Helicobacter pylori. Mol Microbiol 1998, 28:37-53.

5. Yamazaki S, Yamakawa A, Ito Y, Ohtani M, Higashi H, Hatakeyama M, Azuma T: The CagA protein of Helicobacter pylori is translocated into epithelial cells and binds to SHP-2 in human gastric mucosa. J Infect Dis 2003, 187:334-337.

6. Backert S, Moese S, Selbach M, Brinkmann V, Meyer TF: Phosphorylation of tyrosine 972 of the Helicobacter pylori CagA protein is essential for induction of a scattering phenotype in gastric epithelial cells. Mol Microbiol 2001, 42:631-644.

7. Higashi H, Tsutsumi R, Fujita A, Yamazaki S, Asaka M, Azuma T, Hatakeyama M: Biological activity of the Helicobacter pylori virulence factor CagA is determined by variation in the tyrosine phosphorylation sites. Proc Natl Acad Sci U S A 2002, 99:14428-14433.

8. Tammer I, Brandt S, Hartig R, Konig W, Backert S: Activation of Abl by Helicobacter pylori: a novel kinase for CagA and crucial mediator of host cell scattering. Gastroenterology 2007, 132:1309-1319.

9. Selbach M, Moese S, Hauck CR, Meyer TF, Backert S: Src is the kinase of the Helicobacter pylori CagA protein in vitro and in vivo. J Biol Chem 2002, 277:6775-6778.

10. Ren S, Higashi H, Lu H, Azuma T, Hatakeyama M: Structural basis and functional consequence of Helicobacter pylori CagA multimerization in cells. $J$ Biol Chem 2006, 281:32344-32352.

11. Ishikawa S, Ohta T, Hatakeyama M: Stability of Helicobacter pylori CagA oncoprotein in human gastric epithelial cells. FEBS Lett 2009, 583:2414-2418.

12. Sicinschi LA, Correa P, Peek RM, Camargo MC, Piazuelo MB, Romero-Gallo J, Hobbs SS, Krishna U, Delgado A, Mera R, et al: CagA C-terminal variations in Helicobacter pylori strains from Colombian patients with gastric precancerous lesions. Clin Microbiol Infect 2009, 16:369-378.

13. Uchida T, Nguyen LT, Takayama A, Okimoto T, Kodama M, Murakami K, Matsuhisa T, Trinh TD, Ta L, Ho DQ, et al: Analysis of virulence factors of Helicobacter pylori isolated from a Vietnamese population. BMC Microbiol 2009, 9:175.

14. Monstein HJ, Ellnebo-Svedlund K: Molecular typing of Helicobacter pylori by virulence-gene based multiplex PCR and RT-PCR analysis. Helicobacter 2002, 7:287-296.

15. Redeen S, Petersson F, Tornkrantz E, Levander H, Mardh E, Borch K: Reliability of Diagnostic Tests for Helicobacter pylori Infection. Gastroenterol Res Pract 2011, 2011:940650. 
16. Monstein HJ, Olsson C, Nilsson I, Grahn N, Benoni C, Ahrne S: Multiple displacement amplification of DNA from human colon and rectum biopsies: bacterial profiling and identification of Helicobacter pylori-DNA by means of 16S rDNA-based TTGE and pyrosequencing analysis. J Microbiol Methods 2005, 63:239-247.

17. Karlsson A, Ryberg A, Nosouhi Dehnoei M, Borch K, Monstein HJ: Variation in number of cagA EPIYA-C phosphorylation motifs between cultured Helicobacter pylori and biopsy strain DNA. Infect Genet Evol 2011.

18. Monstein HJ, Karlsson A, Ryberg A, Borch K: Application of PCR amplicon sequencing using a single primer pair in PCR amplification to assess variations in Helicobacter pylori CagA EPIYA tyrosine phosphorylation motifs. BMC Res Notes 2010, 3:35.

19. Furuta Y, Yahara K, Hatakeyama M, Kobayashi I: Evolution of cagA oncogene of Helicobacter pylori through recombination. PLoS One 2011, 6:e23499. 


\section{Revised as Notes 2012}

\section{FIG. LEGENDS}

\section{Fig. 1}

A) Schematic drawing of the $\operatorname{cagA}$ gene. M13- and T7-sequence tagged primers M13-pEPIY.T5.SE and T7-CagA.EPIYA.AS used in amplification of the pre-EPIYA/T and EPIYA/T motifs. B) Amino acids flanking the EPIYA/T motifs present in Western EPIYA/TA, EPIYA/T-B and EPIYA/T-C segments of $H$. pylori 26695. CagA multimerisation (CM) amino acids are underlined and in italics. C) Amino acids flanking the EPIYA/T motif present in the East Asian EPIYA/T-D segment. CM amino acids are underlined and in italics.

\section{Fig. 2}

CGE analysis of re-amplified cloned amplicons derived from $H$. pylori-strain HJM18. Primers M13-CagA.EPIYA.SE and T7-CagA.EPIYA.AS were used in PCR amplification (Fig. 1; Table 1). The position of amplicon sizes corresponding to EPIYA/T-AB, -ABC, -ABCC, and -ABCCC compositions are indicated. Lane 18 represents the original amplification using DNA derived from $H$. pylori strain No. 18. Lane 18a - 18k represent amplicons derived from plasmid DNA re-amplification of 11 randomly selected clones. NTC, non-template control. A virtual internal reference marker is indicated in the left margin. 
Revised as Notes 2012

Table $1 H$. pylori cagA genotyping

\begin{tabular}{|c|c|c|}
\hline Strain & $\begin{array}{l}\text { CagA EPIYA/T } \\
\text { genotype }^{a}\end{array}$ & $\begin{array}{c}\text { pre-EPIYA/T } \\
\text { genotype }^{b}\end{array}$ \\
\hline HJM1 & $\mathrm{ABCC}$ & ndt \\
\hline HJM2 & $\mathrm{ABC}$ & ndt \\
\hline HJM3 & $\mathrm{ABC}$ & ndt \\
\hline HJM4 & $\mathrm{ABC}$ & ndt \\
\hline HJM5 & $\mathrm{ABC}$ & ndt \\
\hline HJM6 & $\mathrm{AABC}$ & ndt \\
\hline HJM7 & no amplicon ${ }^{\mathbf{c}}$ & ndt \\
\hline HJM8, corpus ${ }^{\mathbf{d}}$ & $\mathrm{ABC}$ & ndt \\
\hline HJM9, antrum ${ }^{\mathbf{d}}$ & $\mathrm{ABC}$ & ndt \\
\hline HJM10 & $\mathrm{ABC}$ & ndt \\
\hline HJM11 & $\mathrm{ABD}$ & $39 \mathrm{bp}$ \\
\hline HJM12 & $\mathrm{AABC}$ & ndt \\
\hline HJM13 & $\mathrm{ABC}$ & ndt \\
\hline HJM14 & $\mathrm{ABC}$ & ndt \\
\hline HJM15, antrum & $\mathrm{ABC}$ & ndt \\
\hline HJM16, corpus ${ }^{\mathbf{d}}$ & mixed $^{\mathbf{e}}$ & ndt \\
\hline HJM17 & $\mathrm{ABC}$ & ndt \\
\hline HJM18 & mixed $^{\mathbf{e}}$ & ndt \\
\hline HJM20 & $\operatorname{mixed}^{\mathrm{e}}$ & ndt \\
\hline HJM21 & no amplicon ${ }^{\mathbf{c}}$ & ndt \\
\hline HJM22 & $\mathrm{ABC}$ & ndt \\
\hline HJM23 & $\mathrm{ABC}$ & ndt \\
\hline HJM24 & $\mathrm{ABC}$ & ndt \\
\hline HJM25 & $\mathrm{ABC}$ & ndt \\
\hline$H P 26695^{\mathrm{f}}$ & $\mathrm{ABC}$ & ndt \\
\hline
\end{tabular}

abased on amplicon sequencing.

${ }^{\mathbf{b}}$ cagA pre-EPIYA/T nomenclature according to Uchida et al. [13]. ndt: non-deletion type; 39 bp: 39 bp deletion type.

${ }^{\mathbf{c}}$ no sequences generated due to lack of EPIYA/T specific amplicons.

${ }^{\mathbf{d}}$ H. pylori strain HJM8 (corpus) and HJM9 (antrum) and strains HJM15 (antrum) and HJM16 (corpus) originate from the same two patients.

${ }^{\mathbf{e}}$ mixed templates generating mixed DNA sequences

freference strain H. pylori 26695 [GeneBank:NC_000915] 